\title{
HUBUNGAN PARITAS DAN PENDIDIKAN IBU HAMIL DENGAN PENGETAHUAN IBU HAMIL TENTANG KETIDAKYAMANAN PADA MASA KEHAMILAN DI BPM SAGITA PALEMBANG TAHUN 2017
}

\author{
Sri Wahyuningsih \\ STIKES Pembina Palembang \\ Program Studi D-III Kebidanan
}

\author{
Informasi Artikel : \\ Diterima : Agustus 2018 \\ Disetujui : $\quad$ November 2018 \\ "Korespondensi Penulis : \\ wahyuningsihs82@yahoo.com
}

\begin{abstract}
A B S T R A K
Antenatal Care adalah pemeriksaan yang dilakukan ibu hamil pada tenaga kesehatan untuk mendeteksi kehamilan, sehingga ibu lebih siap menghadapi kehamilan dan persalinannya nanti. Tujuan penelitian ini untuk mengetahui hubungan paritas, pendidikan dan pengetahuan ibu hamil dengan ketidaknyamanan pada masa kehamilan di BPM Sagita berjumlah 30 responden. Sampel yang digunakan dalam penelitian ini adalah sampel jenuh. Penelitian ini menggunakan data primer yaitu dari pengisian kuesioner. Kemudian analisa data menggunakan dengan univariat dan bivariat. Hasil uji chi-square menunjukkan ada hubungan paritas ibu $\rho$-value $=0,000 \leq 0,05$. Ada hubungan pendidikan ibu $\rho$-value $=0,000 \leq 0,05$. Disarankan kepada ibu hamil untuk lebih sering melakukan antenatal care karena membuat ibu lebih tahu mengenai kehamilan, menghadapi persalinan dan komplikasi yang mungkin terjadi sehingga dapat lebih diperhitungkan dan dipersiapkan langkah-langkah dalam pertolongan persalinan lebih cepat dan tepat lebih diperhitungkan dan dipersiapkan langkah-langkah dalam pertolongan persalinan lebih cepat dan tepat dalam pemilihan maupun penolong dalam persalinan.
\end{abstract}

Kata Kunci: Paritas, Pendidikan, Pengetahuan, Ketidaknyamanan Pada Masa Kehamilan.

\begin{abstract}
Antenatal care is an examination performed by pregnant women on health workers to detect preganancy. So that, the mother is well prepared to face preganancy later. The purpose of this study was to find out the relationship of parity, education and knowledge of pregnant women with discomfort during pregnancy in BPM Sagita Palembang. Quantitative research design was analytic with Cross-sectional. The population of the study was all pregnant women who were in BPM Sagita amounted to 30 respondents. The sample used in this research was saturated sample. This research used primary data that was from filling questioner. Then the data analyzed using univariate and bivariate. Chi-square test results showed there was a parity relationship $\rho$-value $=0,000 \leq 0,05$. There was a relationship of mother education $\rho$-value $=0,000 \leq 0,05$. There was a relationship of knowledge of pregnant women $\rho$-value $=0,000 \leq 0,05$. It is suggested to pregnant women to do antenatal care more often because it makes mothers know more about pregnancy, to face labor and complication that may occur so that more can be calculated and prepared steps in delivery aid faster and more accurately taken into account and prepared steps in delivery help is faster and more accurate in selection in labor.
\end{abstract}

Keywords : Parity, Education, Knowledge, Discomfort During Pregnancy 


\section{PENDAHULUAN}

Ketidaknyamanan merupakan suatu perasaan ataupun yang tidak menyenangkan bagi kondisi fisik ataupun mental pada ibu hamil (Idayah, 2013). Pada masa kehamilan ibu merasakan ketidaknyaman, antara lain sering kencing, cloasma gravidarum, diare, odema, gatalgatal, gusi berdarah, hemoroid, mengidam, keram pada kaki, konstipasi dan lain-lain. Jika tidak segera di tangani akan mengakibatkan komplikasi, salah satu persiapan yang perlu dilakukan yaitu dengan deteksi dini (Bartini, 2012).

Angka kematian ibu di dunia masih tinggi, terutama di negara-negara berkembang. Setiap hari sekitar 800 perempuan meninggal akibat komplikasi kehamilan atau persalinan di dunia. Secara global pada tahun 2013, diperkirakan ada 289.000 kematian ibu selama dan setelah kehamilan dan persalinan (WHO, 2014).

Angka kematian ibu di Indonesia masih tinggi yaitu 359 per 100.000 kelahiran hidup pada tahun 2012. Angka tersebut menunjukan kenaikan dari tahun 2007 yaitu 228 per 100.000 kelahiran hidup (BPS,2013). Salah satu provinsi di Indonesia yaitu Provinsi Sumatera Selatan, tercatat AKI pada tahun 2011 masih tinggi yaitu 133 kasus per 100.000 kelahiran hidup, tahun 2012 mencapai 149 kasus per 100.000 kelahiran hidup dan tahun 2013 mencapai 146 kasus per 100.000 kelahiran hidup. (Dinkes,2013). Data tersebut menjadikan pada tahun 2015 yaitu 102 per 100.000 kelahiran hidup (Indriyanti dan Asmuji, 2014).

Penyebab kematian ibu di Indonesia didominasi oleh perdarahan, hipertensi dalam kehamilan dan infeksi. Penyebab kematian ibu di Sumatera Selatan terdiri dari penyebab langsung yaitu perdarahan (25\%), ekamsi (13\%), dan sepsis (15\%), hipertensi dalam kehamilan (12\%), partus macet (8\%), komplikasi abortus tidak aman (13\%), dan sebab-sebab lain (8\%). Penyebab tidak langsung yaitu budaya, pendidikan masyarakat, pengetahuan, lingkungan, kecukupan fasilitas kesehatan, sumber daya manusia, dan lain sebagainya (Dinkes, 2013).

Ketidaknyamanan merupakan suatu perasaan ataupun yang tidak menyenangkan bagi kondisi fisik ataupun mental pada ibu hamil (Idayah, 2012)

Paritas adalah jumlah anak yang dilahirkan oleh seseorang ibu baik hidup maupun mati (Manuaba, 2011).

Pendidikan adalah usaha sadar dan terencana untuk mewujudkan suasana belajar dan proses pembelajaran agar peserta didik secara aktif mengembangkan potensi dirinya untuk memiliki kekuatan spritual keagamaan, pngendalian diri kepribadian, kecerdasan, akhlak mulia, serta keterampilan yang diperlukan dirinya dan masyarakat. Pendidikan diperlukan untuk mendapatkan informasi, misalnya hal-hal yang menunjang kesehatan, sehingga dapat meningkatkan kualitas hidup (UU no.20 tahun 2013).

Pengetahuan merupakan hasil dari tahu, dan ini terjadi setelah orang melakukan penginderaan terjadi melalui pancaindra manusia, yakni indera penglihatan, pendengaran, penciuman, rasa, dan raba. Sebagian besar pengetahuan manusia diperoleh melalui mata dan telinga (Notoatmojo, 2012). Pengetahuan adalah : hasil dari tahu yang diperoleh dari hasil belajar (Riyanto, 2014).

\section{METODLOGI PENELTIAN}

Jenis penelitian ini termasuk Kuantitatif bersifat analitik dengan menggunakan rancangan penelitian cross sectional. Populasi dalam penelitian ini adalah ibu hamil yang memeriksakan kehamilannya di BPM Sagita Palembang bulan November 2017.

Sampel adalah bagian dari jumlah dan karakteriksik yang dimilki oleh populasi tersebut (Sugiyono, 2010) Dikarenakan jumlah ibu hamil yang memeriksakan kehamilannya di BPM Sagita Palembang pada bulan November 2017 kurang dari seratus, maka penelitian ini merupakan penelitian populasi. Oleh karena itu sampel yang diambil sejumlah populasi yaitu 30 orang ibu hamil.

\section{HASIL PENELITIAN}

\section{Analisa Univariat}

Tabel 1 Distribusi Responden Berdasarkan Variabel Paritas Di BPM Sagita Palembang Tahun 2017

\begin{tabular}{cccc}
\hline No & Paritas & $\begin{array}{c}\text { Jumlah } \\
(\mathbf{n})\end{array}$ & $\begin{array}{c}\text { Persentase } \\
(\mathbf{\%})\end{array}$ \\
\hline 1. & Multigravida & 20 & 66,7 \\
\hline 2. & Primigravida & 10 & 33,3 \\
\hline & Total & $\mathbf{3 0}$ & $\mathbf{1 0 0}$
\end{tabular}

Berdasarkan Tabel 1 diatas diketahui responden multigravida berjumlah 20 orang $(66,7 \%)$ lebih banyak dari pada responden primigravida yaitu 10 orang $(33,3 \%)$.
Tabel 2 Distribusi Responden Berdasarkan Variabel Pendidikan Di BPM Sagita Palembang Tahun 2017


Jurnal Kebidanan : Jurnal Medical Science Ilmu Kesehatan Akademi Kebidanan Budi Mulia Palembang Volume.8 No.2, Desember 2018

\begin{tabular}{clcc}
\hline No & Pendidikan & $\begin{array}{c}\text { Jumlah } \\
(\mathbf{n})\end{array}$ & $\begin{array}{c}\text { Persentase } \\
(\boldsymbol{\%})\end{array}$ \\
\hline 1. & $\begin{array}{l}\text { Rendah } \\
\text { SMA }\end{array}$ & 9 & 30 \\
\hline 2. & $\begin{array}{l}\text { Tinggi } \\
\geq \text { SMA }\end{array}$ & 21 & 70 \\
\hline & Total & $\mathbf{3 0}$ & $\mathbf{1 0 0}$ \\
\hline
\end{tabular}

Berdasarkan Tabel 2 diatas diketahui responden yang mempunyai pendidikan tinggi berjumlah 21 orang $(70 \%)$ lebih banyak daripada responden yang mempunyai pendidikan rendah yaitu 9 orang $(30 \%)$.

\section{Tabel 3 Distribusi Pengetahuan Ibu Hamil Tentang Ketidaknyamanan Pada Masa Kehamilan Di BPM Sagita Palembang Tahun 2017}

\begin{tabular}{|c|c|c|c|}
\hline No & $\begin{array}{c}\text { Pengetahuan } \\
\text { Tentang } \\
\text { Ketidaknyamanan } \\
\text { Pada Masa } \\
\text { Kehamilan } \\
\end{array}$ & $\underset{(\mathrm{n})}{\text { Jumlah }}$ & $\begin{array}{c}\text { Persentase } \\
(\%)\end{array}$ \\
\hline 1. & Kurang & 8 & 26,7 \\
\hline 2. & Baik & 22 & 73,3 \\
\hline & Total & 30 & 100 \\
\hline
\end{tabular}

Berdasarkan Tabel 2.3 diatas diketahui responden yang mempunyai pengetahuan baik tentang ketidaknyamanan pada masa kehamilan berjumlah 22 orang $(73,3 \%)$ lebih banyak dari pada responden yang mempunyai pengetahuan kurang tentang ketidaknyamanan pada masa kehamilan yaitu 8 orang $(26,7 \%)$.

\section{Analisa Bivariat}

Tabel 4 Distribusi Responden Berdasarkan Paritas dan Pengetahuan Tentang Ketidaknyamanan Pada Masa Kehamilan di BPM Sagita Palembang Tahun 2017

\begin{tabular}{|c|c|c|c|c|c|c|c|c|}
\hline \multirow{3}{*}{ No. } & \multirow{3}{*}{ Paritas } & \multicolumn{4}{|c|}{$\begin{array}{l}\text { Pengetahuan Tentang } \\
\text { Ketidaknyamanan } \\
\text { Pada Masa Kehamilan }\end{array}$} & \multicolumn{2}{|c|}{ Jumlah } & \multirow[t]{3}{*}{ P value } \\
\hline & & \multicolumn{2}{|c|}{$\begin{array}{c}\text { Kurang } \\
\text { Baik }\end{array}$} & \multicolumn{2}{|c|}{ Baik } & \multirow[t]{2}{*}{$\mathbf{N}$} & \multirow[t]{2}{*}{$\%$} & \\
\hline & & $\mathbf{n}$ & $\%$ & $\mathbf{n}$ & $\%$ & & & \\
\hline 1. & Multigravida & 1 & 5 & 19 & 95 & 20 & 100 & \multirow{3}{*}{$\mathbf{0 , 0 0 0}$} \\
\hline & Primigravida & 7 & 70 & 3 & 30 & 10 & 100 & \\
\hline & Jumlah & 8 & 26,7 & 22 & $\mathbf{7 3 , 3}$ & 30 & 100 & \\
\hline
\end{tabular}

Berdasarkan hasil pada Tabel 4 diatas diketahui responden primigravida dan mempunyai pengetahuan kurang tentang

ketidaknyaman pada masa hamil berjumlah 7 responden $(70 \%)$ lebih banyak dari responden multigravida dan mempunyai pengetahuan kurang tentang ketidaknyaman pada masa hamil yaitu berjumlah 3 responden (30\%). Sedangkan responden multigravida dan mempunyai pengetahuan baik tentang ketidaknyaman pada masa hamil berjumlah 19 responden $(95 \%)$ lebih banyak dari responden primigravida dan mempunyai pengetahuan baik tentang ketidaknyaman pada masa hamil yaitu berjumlah 1 responden $(5 \%)$.

Hasil uji chi-square didapatkan nilai $p$ value $=0,000<0,05$ yang artinya ada hubungan yang bermakna antara paritas dengan pengetahuan ibu hamil tentang ketidaknyamanan pada masa kehamilan di BPM Sagita Palembang tahun 2017.

Tabel 5 Distribusi Responden Berdasarkan Pendidikan dan Pengetahuan Tentang Ketidaknyamanan Pada Masa Kehamilan di BPM Sagita Palembang Tahun 2017

\begin{tabular}{|c|c|c|c|c|c|c|c|c|}
\hline \multirow{3}{*}{ No. } & \multirow{3}{*}{ Pendidikan } & \multicolumn{4}{|c|}{$\begin{array}{c}\text { Pengetahuan Tentang } \\
\text { Ketidaknyamanan } \\
\text { Pada Masa Kehamilan }\end{array}$} & \multicolumn{2}{|c|}{ Jumlah } & \multirow[t]{3}{*}{ P value } \\
\hline & & \multicolumn{2}{|c|}{$\begin{array}{c}\text { Kurang } \\
\text { Baik }\end{array}$} & \multicolumn{2}{|c|}{ Baik } & \multirow[t]{2}{*}{$\mathbf{N}$} & \multirow[t]{2}{*}{$\%$} & \\
\hline & & $\mathbf{n}$ & $\%$ & $\mathbf{n}$ & $\%$ & & & \\
\hline 1. & $\begin{array}{l}\text { Pendidikan } \\
\text { Rendah }\end{array}$ & 7 & 77,8 & 2 & 22,2 & 9 & 100 & \\
\hline 2. & $\begin{array}{l}\text { Pendidikan } \\
\text { Tinggi }\end{array}$ & 1 & 4,8 & 20 & 95,2 & 21 & 100 & 0,000 \\
\hline & Jumlah & 8 & 26,7 & 22 & 73,3 & 30 & 100 & \\
\hline
\end{tabular}

Berdasarkan hasil pada Tabel 5 diatas diketahui responden yang Pendidikan rendah dan mempunyai pengetahuan kurang tentang ketidaknyaman pada masa hamil berjumlah 7 responden $(77,8 \%)$ lebih banyak dari responden yang pendidikan tinggi dan mempunyai pengetahuan kurang tentang ketidaknyaman pada masa hamil yaitu berjumlah 2 responden $(22,2 \%)$. Sedangkan responden yang pendidikan tinggi dan mempunyai pengetahuan baik tentang ketidaknyaman pada masa hamil berjumlah 20 responden $(95,2 \%)$ lebih banyak dari responden yang pendidikan rendah dan mempunyai pengetahuan baik tentang ketidaknyaman pada masa hamil yaitu berjumlah 2 responden $(22,2 \%)$.

Hasil uji chi-square didapatkan nilai $p$ value $=0,000<0,05$ yang artinya ada hubungan yang bermakna antara pendidikan dengan pengetahuan ibu hamil tentang ketidaknyamanan 
pada masa kehamilan di BPM Sagita Palembang tahun 2017.

\section{PEMBAHASAN}

\section{Paritas}

Berdasarkan hasil penelitian yang dilakukan di BPM Sagita pada bulan November 2017 didapatkan paritas primigravida berjumlah 20 orang $(66,7 \%)$ lebih banyak dari pada responden yang mempunyai paritas multigravida yaitu 10 orang $(33,3 \%)$. Paritas adalah jumlah anak yang dilahirkan oleh seseorang ibu baik hidup maupun mati (Manuaba, 2011).

Hasil peneltian ini sejalan dengan penelitian Jasmine, 2013 yang berjudul "Hubungan Paritas Dan Usia Terhadap Kunjungan K4 Di BPM Hj. Maimunah Palembang Tahun 2013" dengan hasil paritas multigravida lebih banyak dibanding dengan paritas lainnya.

Dari hasil penelitian ini penulis berasumsi bahwa ibu multigravida memiliki kesadaran yang lebih baik tentang pentingnya melakukan kunjungan ANC, sehingga pada saat melakukan penelitian lebih banyak responden dengan paritas multigravida yang ditemui di BPM Sagita Palembang.

\section{Pendidikan}

Berdasarkan hasil penelitian yang dilakukan di BPM Sagita pada bulan November 2017 didapatkan responden yang mempunyai pendidikan tinggi berjumlah 21 orang $(70 \%)$ lebih banyak daripada responden yang mempunyai pendidikan rendah yaitu 9 orang (30\%). Pendidikan adalah usaha sadar dan terencana untuk mewujudkan suasana belajar dan proses pembelajaran agar peserta didik secara aktif mengembangkan potensi dirinya untuk memiliki kekuatan spritual keagamaan, pngendalian diri kepribadian, kecerdasan, akhlak mulia, serta keterampilan yang diperlukan dirinya dan masyarakat. Pendidikan diperlukan untuk mendapatkan informasi, misalnya hal-hal yang menunjang kesehatan, sehingga dapat meningkatkan kualitas hidup (UU no.20 tahun 2013).

Hasil peneltian ini sejalan dengan penelitian Rukaiyah, 2015 dengan judul "Hubungan Pendidikan Dan Usia Dengan Keteraturan Melakukan ANC Di BPM $\mathrm{Hj}$. Zaleha Tugu Mulyo Tahun 2015" hasil penelitiannya menyatakan bahwa ibu hamil yang berpendidikan SMA dan PT lebih banyak dibanding dengan ibu tidak tamat SMA.

Dari hasil penelitian ini penulis berasumsi bahwa ibu yang berpendidikan tinggi memiliki kesadaran yang lebih baik tentang pentingnya melakukan kunjungan ANC, sehingga pada saat melakukan penelitian lebih banyak responden berpendidikan tinggi yang ditemui di BPM Sagita Palembang.

\section{Pengetahuan}

Berdasarkan hasil penelitian yang dilakukan di BPM Sagita pada bulan November 2017 didapatkan responden yang mempunyai pengetahuan baik tentang ketidaknyamanan pada masa kehamilan berjumlah 22 orang $(73,3 \%)$ lebih banyak dari pada responden yang mempunyai pengetahuan kurang tentang ketidaknyamanan pada masa kehamilan yaitu 8 orang $(26,7 \%)$.

Pengetahuan adalah : hasil dari tahu yang diperoleh dari hasil belajar, khususnya tentang ketidaknyamanan pada masa kehamilan (Riyanto, 2014).

Hasil peneltian ini sejalan dengan penelitian Faizatul Ummah (2014), dengan judul "Ibu Hamil dengan pengetahuan Ketidaknyamanan pada masa kehamilan di BPM Hj, Siti Istri Murtiningsih Amd. Keb di Desa Babat Kecamatan Babat Kabupaten Lamongan" hasil penelitiannya menyatakan bahwa ibu hamil yang mempunyai pengetahuan baik tentang ketidaknyamanan pada masa kehamilan lebih banyak dibanding dengan ibu hamil yang mempunyai pengetahuan kurang baik tentang ketidaknyamanan pada masa kehamilan.

Dari hasil penelitian ini penulis berasumsi bahwa ibu yang berpengetahuan tinggi akan lebih berusaha untuk menjaga kesehatannya semasa kehamilan sampai persalinan, untuk itu ia akan lebih rajin untuk melakukan ANC, sehingga pada saat melakukan penelitian di BPM Sagita Palembang responden yang berpengetahuan tinggi lebih banyak ditemui.

\section{Paritas Dengan Pengetahuan Tentang Ketidaknyamanan Pada Masa Kehamilan}

Berdasarkan hasil uji chi-square untuk mengetahui hubungan antara paritas dengan pengetahuan ibu hamil tentang ketidaknyamanan pada masa kehamilan didapatkan nilai $p$ value $=0,000$ yang jika 
dibandngkan dengan nilai $\alpha=0,05$, maka nilai $p$ value $\leq 0,05$ yang berarti ada hubungan yang bermakna antara paritas dengan pengetahuan ibu hamil tentang ketidaknyamanan pada masa kehamilan di BPM Sagita Palembang tahun 2017.

Pengetahuan yang baik tetang ketidaknyaman pada masa kehamilan dapat mencegah terjadinya komplikasi selama kehamilan serta BBLR, karena jika ibu hamil memiliki pengetahuan yang baik tentang ketidaknyaman pada masa kehamilan ia berusaha mengikuti saran-saran dari petugas kesehatan selama masa kehamilannya, seperti makan sedikit tapi sering untuk mengatasi mual muntah, istirahat yang cukup untuk mencegah terjadinya anemia dan menghindari stress yang berlebih, ibu dengan paritas multipara memiliki pengetahuan dan pengalaman yang lebih banyak tentang hal tersebut dibanding ibu yang baru pertama kali hamil (Sri hastati, 2010).

Hasil peneltian ini sejalan dengan penelitian Jasmine, 2013 yang berjudul "Hubungan paritas dan usia terhadap Kunjungan K4 di BPM Hj. Maimunah Palembang tahun 2013" dengan hasil paritas multigravida berpeluang 4 kali lebih besar untuk melakukan kunjungan K4 dibanding dengan paritas lainnya, oleh karena itu pengetahuannya tentang kehamilan lebih banyak dibanding ibu dengan primipara.

Berdasarkan hasil penelitian serta teori yang ada maka penulis berpendapat bahwa ada hubungan paritas dengan pengetahuan ibu hamil tentang ketidaknyamanan pada masa kehamilan, karena seorang ibu yang telah hamil dan melahirkan lebih dari satu kali akan memiliki pengetahuan dan pengalaman tentang kehamilan yang lebih banyak jika dibanding ibu yang pertama kali hamil.

\section{Pendidikan Dengan Pengetahuan Tentang Ketidaknyamanan Pada Masa Kehamilan}

Berdasarkan hasil uji chi-square untuk mengetahui hubungan antara pendidikan dengan pengetahuan ibu hamil tentang ketidaknyamanan pada masa kehamilan didapatkan nilai $p$ value $=0,000$ yang jika dibandngkan dengan nilai $\alpha=0,05$, maka nilai $p$ value $\leq 0,05$ yang berarti ada hubungan yang bermakna antara pendidikan dengan pengetahuan ibu hamil tentang ketidaknyamanan pada masa kehamilan di BPM Sagita Palembang tahun 2017.
Pendidikan dapat mempengaruhi seseorang, termasuk juga perilaku seseoarang akan pola hidup, terutama dalam memotivasi untuk sikap berperan serta dalam pembangunan, pada umumnya makin tinggi pendidikan seseorang makin mudah menerima informasi (Y.B. Mantra, 2013). Ibu hamil dengan latar belakang pendidikan tinggi memiliki kemampuan yang lebih besar untuk memahami informasi yang diberikan, sehingga ia akan lebih mudah untuk mengadopsi dan mengikuti anjuran yang diberikan petugas kesehatan tentang bagaimana menjaga kehamilan.

Hasil peneltian ini sejalan dengan penelitian Rukaiyah, 2015 dengan judul "Hubungan pendidikan dan usia dengan Pengetahuan keteraturan melakukan ANC di BPM Hj. Zaleha Tugu Mulyo tahun 2015" hasil penelitiannya menyatakan bahwa ibu hamil yang berpendidikan SMA dan PT berpeluang 3 kali lebih besar untuk melakukan kunjungan ANC secara teratur dibanding dengan ibu hamil yang berpendidikan dibawah SMA.

Berdasarkan hasil penelitian serta teori yang ada maka penulis berpendapat bahwa ada hubungan pendidikan dengan pengetahuan ibu hamil tentang ketidaknyamanan pada masa kehamilan, karena seorang ibu memiliki latar belakang pendidikan yang tinggi akan lebih mudah untuk menerima dan memahami informasi yang diberikan.

\section{KESIMPULAN}

1. Distribusi responden yang mempunyai paritas primigravida berjumlah 10 orang $(33,3 \%)$ lebih banyak daripada responden yang mempunyai paritas multigravida yaitu 20 orang $(66,7 \%)$.

2. Distribusi responden yang mempunyai pendidikan tinggi berjumlah 21 orang $(70 \%)$ lebih banyak dari pada responden yang mempunyai pendidikan rendah yaitu 9 orang $(30 \%)$

3. Distribusi responden yang mempunyai pengetahuan baik tentang ketidaknyamanan pada masa kehamilan berjumlah 22 orang $(73,3 \%)$ lebih banyak daripada responden yang mempunyai pengetahuan kurang tentang ketidaknyamanan pada masa kehamilan yaitu 8 orang $(26,7 \%)$.

4. Ada hubungan yang signifikan antara paritas dengan pengetahuan ibu hamil tentang ketidaknyaman pada masa kehamilan di BPM Sagita Palembang Tahun 2017 dapat dilihat dari nilai $p$ value $0,000 \leq 0,05$.

5. Ada hubungan yang signifikan antara pendidikan dengan dengan pengetahuan ibu 
Jurnal Kebidanan : Jurnal Medical Science Ilmu Kesehatan Akademi Kebidanan Budi Mulia Palembang Volume.8 No.2, Desember 2018

hamil tentang ketidaknyaman pada masa kehamilan di BPM Sagita Palembang Tahun 2017 dapat dilihat dari nilai $p$ value $0,000 \leq$ 0,05 .

\section{SARAN}

\section{Bagi BPM Sagita Palembang}

Perlu dilakukan konseling yang lebih intensif kepada ibu hamil yang memeriksakan kehamilannya di BPM Sagita tentang cara-cara mengatasi keluhan serta ketidaknyamanan dimasa kehamilan, untuk mencegah erat mengurangi terjadinya komplikasi selama masa.

\section{Bagi Responden}

Diharapkan para ibu hamil lebih meluangkan waktu untuk mencari informasi tentang kesehatan dimasa kehamilan, agar ibu selalu sehat dimasa kehamilan, proses persalinan lancar dan bayi lahir dalam keadaaan sehat.

\section{Bagi Institusi Pendidikan}

Diharapkan penelitian ini sebagai bahan referensi atau bahan informasi bagi peneliti yang akan datang yang ingin melakukan penelitian terhadap pengetahuan ibu hamil.

\section{DAFTAR PUSTAKA}

Astutea, Sri. 2017. Asuhan Pada Masa Kehamilan. Jakarta : PT. Gelora Aksara Pratama

Bartini. 2012." Asuhan Kehamilan”. Jakarta : PDF,adobereader

Depkes Kota Palembang, Profil Dinas Kesehatan Kota Palembang 2013 : www.depkes.go.id

Depkes RI. Laporan Riskesdas 2012. 2012. http://www.riskesdas.litbang.dep kes.go.id/download/Laporan_risk esdas_2012.pdf

Dini, Komala. Sari." Tingkat Pendidikan Secara Teori " woropress. Com

Hidayat, AAA. 2014. "Metode Penelitianndan Teori Analisa”. Jakarta : Salemba Medika

Icemi, Sukarmi. 2013. "Asuhan Kebidanan". Puwokerto : PDF (secured).

Iadaya. 2012.” Ilmu Kesehatan”. Jakarta : PDF
Indra Susanti, Ari. 2017. "Asuhan Pada Masa Kehamilan”. Erlangga : PT. Gelora Akasara Pratama

Indrayanti, Asmuji. 2014. "Angka Kematian Ibu”. Jakarta : PDF. ac. Id

Jasmine, 2013 . Hubungan Paritas Dan Usia Terhadap Kunjungan K4 BPM $\mathrm{Hj}$. MAimunah Palembang Tahun 2013

Kemenkes, RI. 2015. "Asuhan Kebidanan". Jakarta: PDF (secured), id.

Kusmiyati. 2012. "Asuhan Kebidanan". Purwokerto: PDF (secured).

Mandiri Ariyanti.2017. "Asuhan Pada Masa Kehamilan”. Erlangga : PT. Gelora Aksara Pratama.

Manuaba IBG. 2012 Ilmu Kebidanan Patologi. Jakarta : Buku Kedokteeran EGC

Notoatmodjo S. 2010. Ilmu kesehatan masyarakat prinsip-prinsip dasar. Jakarta :PT Rineka Cipta

2010. Metodologi Penelitian. Jakarta: Rineka Cipta

2012. Ilmu kesehatan masyarakat dan seni. Jakarta :PT Rineka Cipta

Novianti. H, 2016. Pengaruh Usia dan Paritas Terhadap Kejadian Preklampsia Di RSUD Sidoarjo. Jurnal Ilmu Kesehatan Vol 4 No.2 Desember 2016

Prawirohardjo, Sarwono. 2012. "Ilmu Kebidanan Komfrehensif.”Puwekerto : PT.Bina Pustaka

Riyanto A. 2014 KApita Selekta Kuesioner. Salemba Medika

Rukaiyah, 2015. Hubungan Antara Pendidikan dan Usia Dengan Keteraturan Melakukan ANC di BPM Zaleha Tugu Mulyo .http://pustaka /wpcontent/uploads/201/503/rukaiyah130920120037.pdf

Sajiatini, dkk. 2010. "Asuhan Kebidanan Komperhensif ".Puwekerto : PT. Bina Pustaka 
Syeh Aceh, 2013 “ Pengategorian Variabel Penelitian".Wordpres,com.

Sugiyono.2010. Statistik untuk penelitian. Bandung: CV Alfabeta

WHO.2014. "Angka Kematian Ibu". Jakarta : PDF.ac.id 
